\title{
BMJ Open Growth trajectories in the children of mothers with eating disorders: a longitudinal study
}

Abigail Easter, ${ }^{1,2}$ Laura D Howe, ${ }^{3,4}$ Kate Tilling, ${ }^{3,4}$ Ulrike Schmidt, ${ }^{2}$ Janet Treasure, ${ }^{2}$ Nadia Micali ${ }^{1}$

To cite: Easter A, Howe LD, Tilling $\mathrm{K}$, et al. Growth trajectories in the children of mothers with eating disorders:

a longitudinal study. $B M J$ Open 2014;4:e004453. doi:10.1136/bmjopen-2013004453

- Prepublication history and additional material is available. To view please visit the journal (http://dx.doi.org/ 10.1136/bmjopen-2013004453).

$\overline{\mathrm{AE} \text { and } \mathrm{LDH}}$ are joint first authors.

Received 10 November 2013 Revised 3 February 2014 Accepted 20 February 2014

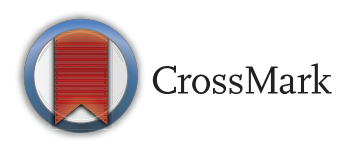

${ }^{1}$ Behavioural and Brain Sciences Unit, University College London, Institute of Child Health, London, UK

2Department of Psychological Medicine and Psychiatry, Institute of Psychiatry, Kings College London, London, UK

${ }^{3}$ School of Social and Community Medicine, University of Bristol, Bristol, UK

${ }^{4} \mathrm{MRC}$ Integrative

Epidemiology Unit at the University of Bristol, University of Bristol, Bristol, UK

Correspondence to Dr Abigail Easter; a.easter@ucl.ac.uk

\section{ABSTRACT}

Objective: The aim of this study was to examine longitudinal patterns of growth trajectories in children of women with eating disorders (ED): anorexia nervosa (AN) and bulimia nervosa (BN).

Design: Prospective longitudinal birth cohort; Avon Longitudinal Study of Parents and Children (ALSPAC).

Setting: South West England, UK.

Participants: The sample consisted of women and their children ( $n=10$ 190) from ALSPAC. Patterns of growth among children of women reporting a history of AN $(n=137)$, BN $(n=165)$, both AN and BN $(n=68)$ and other psychiatric disorders $(n=920)$ were compared with an unexposed group of children $(\mathrm{n}=8900)$.

Main outcome measures: Height and weight data, from birth to 10 years, were extracted from health visitor records, parental report from questionnaires and clinic attendances. Growth trajectories were analysed using mixed-effects models and constructed separately for male and female children.

Results: Between birth and 10 years, male children of women with $\mathrm{BN}$ were taller than children in the unexposed group. Male children of women with a history of AN and BN, and female children of women with AN, were shorter throughout childhood. Between the ages of 2 and 5 , higher body mass index (BMI) was observed in male children in all maternal ED groups. Conversely, female children of women with AN had a BMI of $-0.35 \mathrm{~kg} / \mathrm{m}^{2}$ lower at 2 years compared with the unexposed group, with catch-up by age 10 .

Conclusions: Early childhood growth has been found to predict weight gain in adolescence and adulthood, and may be a risk factor for the development of an ED. These findings therefore have public health implications in relation to the prevention of weightrelated and eating-related disorders later in life.

\section{INTRODUCTION}

Eating disorders (ED), such as anorexia nervosa (AN) and bulimia nervosa (BN), are a common cause of psychiatric morbidity in women of childbearing age. ${ }^{1} \mathrm{AN}$ is characterised by the restriction of energy intake,

\section{Strengths and limitations of this study}

- This is the first large prospective longitudinal study of childhood growth in children of mothers with eating disorders.

- The study benefits from a large number of repeated measurements of childhood growth, between birth and 10 years, and information on confounding factors.

- Maternal eating disorder classification was made on the basis of maternal self-report and according to lifetime history, which may be subject to bias and may represent a range of eating disorder severities and duration of illness.

resulting in a significantly low body weight for age and height, an intense fear of gaining weight or becoming fat and a disturbance in body image which has an undue influence on self-evaluation. The main features of $\mathrm{BN}$ are recurrent binge eating combined with inappropriate compensatory behaviours, such as selfinduced vomiting and misuse of laxatives. ${ }^{2}$

The risk for developmental problems in children of parents with psychiatric disorders has been well documented. Several aspects of child development, including physical, cognitive, emotional and behavioural, have all been shown to be affected. ${ }^{3}$ Until relatively recently, few studies have investigated associations between parental ED and their child's development.

There is preliminary evidence to suggest that children of mothers with ED are at risk for adverse developmental outcomes during child$\operatorname{hood}^{4}$ and are also vulnerable to the developing disordered eating themselves. ${ }^{5}$ Several studies have now highlighted that the prevalence of feeding difficulties is elevated in children of mothers with $\mathrm{AN}$ and $\mathrm{BN}$ during infancy. ${ }^{6-12}$

Moreover, children of women with ED have been found to have different patterns of macronutrient intake and adhere to different dietary patterns, compared with children 
of women without ED, which may have implications for their physical development. ${ }^{13}$ Specifically, we have previously demonstrated that children of mothers with ED are more likely to follow a 'health conscious or vegetarian' dietary pattern and less likely have a 'traditional' dietary pattern, compared with children of mothers without ED.

ED during pregnancy are associated with an increased risk of intrauterine growth restriction and low birthweight deliveries. ${ }^{14}{ }^{15}$ Some studies suggest that adequate postnatal catch-up growth may occur in favourable environments, ${ }^{12} 16$ yet others indicate that poor growth may continue throughout infancy and childhood. ${ }^{17-19}$ While reduced growth has been highlighted in children of women with $\mathrm{AN},{ }^{17} 1820$ there is some evidence that $\mathrm{BN}$ is associated with more rapid growth or obesity in the offspring. ${ }^{7} 1819$

There have been few studies of growth in this group, particularly among older children. In a small clinical sample of 13 mothers with $\mathrm{ED},{ }^{18} 32 \%$ reported that their offspring had abnormal weight or growth for their age. Children of women with AN in this study, in particular female children, were found to be lighter than children of women with $\mathrm{BN}$, and there was evidence of wasting in $46 \%$ of the children investigated.

In the only follow-up study, Stein $e t a l^{11}$ reported that children of women with ED had lower weight gain at 1 year compared with controls and children of women with postnatal depression. ${ }^{21}$ By 10 years of age, the body mass index (BMI) of the children born to mothers with ED was more comparable to the control group. ${ }^{22}$

However, the majority of previous investigations have been limited by small sample size and include children at different ages, making the findings difficult to generalise. Longitudinal studies of growth in children of women with $\mathrm{ED}$, which distinguish between maternal ED diagnostic classifications and child gender, are necessary to investigate whether problematic growth in children of women with ED is limited to early infancy or persists throughout childhood.

\section{Objectives}

The aims of this study were to investigate: (1) whether growth trajectories: height, ponderal index (PI) and BMI, from birth until 10 years, differ between children of women with and without lifetime ED (ie, self-report of ED referring to pre-pregnancy); (2) whether associations of maternal ED with offspring growth are specific to ED or more general psychopathology and (3) whether there are gender differences in the associations of maternal ED with child growth trajectories, since it has previously been demonstrated that adherence to specific dietary patterns is different for male and female children of mothers with ED. ${ }^{13}$

\section{METHODS}

Participants and setting

This study is based on data collected from the Avon Longitudinal Study of Parents and Children
(ALSPAC). ${ }^{23}$ ALSPAC is a longitudinal birth cohort study, the full details of which have been described in detail elsewhere. ${ }^{24} 25$ Briefly, pregnant women living within Avon, with an expected delivery date between 1 April 1991 and 31 December 1992, were invited to participate. Of these women, 14541 were recruited; 14062 (96.7\%) were live-births and 13988 were alive at 1 year.

\section{Measures}

\section{Exposure}

At 12 weeks gestation, women were asked if they had a history of psychiatric problems, including depression, schizophrenia, alcohol abuse, AN, BN and other disorders. Children were classified on the basis of mothers' self-reported maternal psychiatric disorder status. Children of mothers reporting a lifetime history of AN, $\mathrm{BN}$ or both $(\mathrm{AN}+\mathrm{BN})$ and mothers with other psychiatric disorders were compared with the remaining sample of women, who reported no history of a psychiatric disorder. The $\mathrm{AN}+\mathrm{BN}$ category refers to women reporting a history of $\mathrm{AN}$ and $\mathrm{BN}$ during their lifetime. Mothers with a history of an ED and comorbid psychiatric disorder were included and analysed within ED categories.

Although self-reported psychiatric history may be subject to bias, a previous investigation of ED behaviours (eg, self-induced vomiting and laxative use) and cognitions (eg, shape and weight concern) in this sample of women provides support for the use of mothers' selfreported diagnosis of lifetime ED status. ${ }^{26}$

\section{Measures of height and adiposity}

Birth weight was extracted from the medical records, and birth length was measured by ALSPAC staff soon after birth (median 1 day, range 1-14 days). Height and weight data were extracted from health visitor records, parental report from questionnaires and research clinic attendances. From age 7 , all children were invited to annual clinics, and standing height and weight were measured. Full details of the measurement protocols are presented in the online supplementary material. PI was calculated as weight $(\mathrm{kg})$ divided by height $(\mathrm{m})$ cubed, and BMI was calculated as weight $(\mathrm{kg})$ divided by height (m) squared.

Sociodemographic data: Maternal age, educational attainment, smoking and parity were reported in the antenatal mother's questionnaires. Gestational age at birth was estimated from clinical records. Maternal height and weight were self-reported from the questionnaire administered at 12 weeks gestation and used to calculate prepregnancy maternal BMI.

\section{Exclusion and inclusion criteria}

Only singleton pregnancies were included; women were excluded from the current study if they did not respond to the 12-week questionnaire $(n=2019)$ or if their child did not have at least one height/weight measure and full data on potential confounders. 


\section{Statistical analysis}

The number of growth measurements and ages at which they were taken was very variable between children. A methodology was therefore required to create comparable growth variables for each child, regardless of when and how often they were measured; multilevel modelling is one way to do this. Individual growth trajectories were modelled using multilevel models (two levels: measurement occasion and individual) in the statistical package MLwiN, ${ }^{27}$ using fractional polynomials to identify the best-fitting curves. Full methodology is presented in the online supplementary material. Such models allow for the change in scale and variance of growth over time and use all available data under a missing at random assumption. They also allow for individual variation in growth trajectories, as random effects allow each individual to have different intercepts and slopes.

Given the differences in growth during childhood in males and females, and potential gender-specific effects of maternal ED, trajectories were modelled separately for boys and girls. There is a lack of consensus in relation to the measurement of adiposity in infants, but some researchers favour PI over BMI in infants. Furthermore, patterns of BMI change in early childhood are extremely complicated. Given this, PI $\left(\mathrm{kg} / \mathrm{m}^{3}\right)$, rather than BMI, was used as the measure of adiposity from birth to 2 years. BMI was modelled from 2 to 10 years and height from birth to 10 years. Implausible height and weight measurements $(>4$ SD from the mean for gender-specific and age-specific category, approximately $0.1 \%$ of all measurements) were recoded as missing.

Health visitor measurements of height and weight have good accuracy, ${ }^{28}$ but measurements recorded by the children's carers in questionnaires are likely to be less accurate. ${ }^{29}$ Therefore, a binary indicator of measurement source (research clinic or health records vs questionnaire) was included in all models.

Differences in growth trajectories by maternal ED groups ( $\mathrm{AN}, \mathrm{BN}$ and $\mathrm{AN}+\mathrm{BN}$ ) were estimated by fitting interaction terms in the multilevel models between the maternal ED group and the constant term (representing birth length, PI at birth or BMI at age 2) and each of the polynomial terms. This generates separate average growth trajectories for children in each of the maternal groups. Growth trajectories are plotted visually to assess differences by ED group, and multilevel models were used to predict average height, PI and BMI at different ages in each ED group. Z-tests were used to assess the statistical evidence for the differences in anthropometry, comparing each group with the unexposed group (offspring of women with no ED or other psychiatric disorder) at various ages.

Potential difference in childhood growth trajectories were first assessed in unadjusted models; as a second stage of analysis standard confounders (eg, gestational age, maternal age, maternal education and parity) previously found to affect childhood growth were included in all models. Finally, variables thought to lie on the causal pathway between the exposure of interest and the outcome (eg, maternal prepregnancy BMI and smoking during pregnancy), therefore potentially mediating the effect of maternal ED on child growth, were included in the model.

\section{RESULTS}

\section{Sociodemographic data}

Data included in the PI model were available on 10190 children: 4962 girls and 5228 boys, $72.7 \%$ of the full ALSPAC cohort alive at 1 year. Of these children, 137 $(1.3 \%)$ mothers reported a history of AN, 165 (1.6\%) reported a history of $\mathrm{BN}, 68(0.7 \%)$ reported a history of $\mathrm{AN}$ and $\mathrm{BN}$ and $920(9 \%)$ mothers reported a history of another psychiatric disorder. The remaining 8900 (87.3\%) mothers reported no psychiatric disorder history and formed the unexposed comparison group.

There was a median of seven growth measurements per child, with most children having measurements at birth and several measures across the full age range under study (etable 2).

Table 1 outlines the maternal characteristics of women with and without a history of ED. Child gender, maternal age, education and parity were comparable across groups. Pre-pregnancy BMI of women with AN $\left(21.3 \mathrm{~kg} / \mathrm{m}^{2}\right)$ and AN+BN $\left(21.5 \mathrm{~kg} / \mathrm{m}^{2}\right)$ was lower $(\mathrm{p}<0.001)$ compared to women in the unexposed group $\left(22.9 \mathrm{~kg} / \mathrm{m}^{2}\right)$.

\section{Birth length and height differences across ED group}

Unadjusted analyses of birth length and height differences are displayed in the online supplementary material (see etable 3 and efigure 1).

\section{Male children}

After adjustment for confounders, predicted heights for male children in the maternal AN (between birth and 5 years) and BN (between birth and 10 years) groups were higher than children in the unexposed group (see table 1). In the maternal $\mathrm{BN}$ group, this difference widened with age, and at 10 years they were on average $1.88 \mathrm{~cm} \quad(p=0.01)$ taller (see table 2). In contrast, by 10 years of age, children of women with AN were $0.75 \mathrm{~cm}$ shorter $(\mathrm{p}=0.38)$.

In contrast, children of women reporting $\mathrm{AN}+\mathrm{BN}$ and other psychiatric disorders were shorter throughout childhood (see table 2), with the largest difference observed in children of women with other psychiatric disorders. Entering potential mediators slightly attenuated the association (see table 3 ).

\section{Female children}

In adjusted analyses, female children of women with AN had a predicted birth length of $0.47 \mathrm{~cm} \quad(\mathrm{p}=0.07)$ shorter than children in the unexposed group. Furthermore, predicted height values in female children of women with AN (between birth and 10 years) and AN 
Table 1 Prevalence of maternal eating disorders and characteristics of women with/without eating disorders and their offspring (shown for the 10190 children included in ponderal index models)

\begin{tabular}{|c|c|c|c|c|c|}
\hline & $\begin{array}{l}\text { Unexposed } \\
\text { women }\end{array}$ & $\begin{array}{l}\text { Women with } \\
\text { AN }\end{array}$ & $\begin{array}{l}\text { Women with } \\
\text { BN }\end{array}$ & $\begin{array}{l}\text { Women with } \\
\text { AN+BN }\end{array}$ & $\begin{array}{l}\text { Women with other } \\
\text { psychiatric disorders }\end{array}$ \\
\hline $\mathrm{N}(\%)$ & 8900 (87.3) & $137(1.3)$ & $165(1.6)$ & $68(0.7)$ & $920(9.0)$ \\
\hline Male offspring, $\mathrm{N}(\%)$ & $4537(51.0)$ & 73 (53.3) & $84(50.9)$ & 38 (55.9) & $496(53.9)$ \\
\hline \multicolumn{6}{|l|}{ Maternal education, N (\%) } \\
\hline$<$ O-level & $2397(26.9)$ & $33(24.1)$ & $35(21.2)$ & $11(16.2)$ & $341(37.1)$ \\
\hline O-level & 3169 (35.6) & $35(25.6)$ & $58(35.2)$ & $16(23.5)$ & $330(35.9)$ \\
\hline A-level & $2114(23.8)$ & $38(27.7)$ & $46(27.9)$ & $24(35.3)$ & $164(17.8)$ \\
\hline Degree & $1220(13.7)$ & $31(22.6)$ & $26(15.8)$ & $17(25.0)$ & $85(9.2)$ \\
\hline Maternal parity, mean (SD) & $0.81(0.9)$ & $0.89(1.1)$ & $0.78(1.0)$ & $0.87(1.0)$ & $0.98(1.1)$ \\
\hline $\begin{array}{l}\text { Maternal prepregnancy BMI }\left(\mathrm{kg} / \mathrm{m}^{2}\right) \text {, } \\
\text { mean }(\mathrm{SD})\end{array}$ & $22.9(3.8)$ & $21.4(2.9)^{\star \star}$ & $22.93(3.9)$ & $21.5(3.1)^{\star \star}$ & $23.1(4.1)$ \\
\hline Maternal age (years) & $28.4(5.4)$ & $29.1(4.8)$ & $28.32(4.7)$ & $29.3(4.6)$ & $28.5(5.4)$ \\
\hline
\end{tabular}

$+\mathrm{BN}$ (between 1 year and 10 years) were lower than children in the unexposed group (table 2).

Compared with children in the unexposed group, female offspring in the maternal $\mathrm{AN}+\mathrm{BN}$ were slightly longer at birth (difference $0.23 \mathrm{~cm}, \mathrm{p}=0.52$ ), but at 2 and 10 years they were on average $0.93 \mathrm{~cm}(\mathrm{p}=0.22)$ and $0.32 \mathrm{~cm}$ shorter $(\mathrm{p}=0.77)$.

In early childhood, the heights of female children of women with $\mathrm{BN}$ were similar to the unexposed group; by 5 years of age, they were slightly shorter (difference $0.18 \mathrm{~cm}, \mathrm{p}=0.68)$; by 10 years, this difference widened to $0.64 \mathrm{~cm}(\mathrm{p}=0.38)$ shorter than for children in the unexposed group (see table 2 ).

These patterns remained similar when potential mediators were entered into the model (see table 3).

Female children in the other psychiatric disorder group also tended to be shorter throughout childhood; however, these differences were of lower magnitude than the differences observed for the $\mathrm{AN}$ and $\mathrm{AN}+\mathrm{BN}$ groups, see table 2 .

\section{$\mathrm{PI}$ and BMI differences across the ED group}

Unadjusted analyses of PI and BMI are displayed in the supplementary web material (see etable 3 and efigures 2 and 3.

\section{Male children}

Figures 1 and 2 illustrate some group differences in the PI and BMI trajectories of male children. Statistical evidence of these growth differences existed for some but not all of the growth periods studied; in many cases, the coefficients had large SDs, which is unsurprising given the small number of children in each maternal ED group.

In adjusted analyses, PI was lower in male children of women with AN, compared with the unexposed group. Between the ages of 2 and 10 years, children of women in all ED groups had higher BMI than children in the unexposed group. The largest differences were observed at 5 years in the maternal AN group, and children's predicted BMI was $0.34 \mathrm{~kg} / \mathrm{m}^{2}(\mathrm{p}=0.04)$ higher than children in the unexposed group. At 10 years, the BMI of male children of women with $\mathrm{AN}$ and $\mathrm{AN}+\mathrm{BN}$ was more compared to children in the unexposed group (see table 2). These differences persisted after potential mediators were included in the model (see table 3). Male children of mothers with other psychiatric disorders tended to have higher PI at 2 years, but BMI trajectories later in childhood were comparable to children in the unexposed group.

\section{Female children}

As shown in figure 3, the PI of female children of women with $\mathrm{BN}$ was higher than the unexposed group at birth $\left(+0.48 \mathrm{~kg} / \mathrm{m}^{3}, \mathrm{p}=0.04\right)$; by 12 months, this difference had reduced $\left(+0.06 \mathrm{~kg} / \mathrm{m}^{3}, \mathrm{p}=0.81\right)$. The PI at birth of female children of women with $\mathrm{AN}$ and $\mathrm{AN}+\mathrm{BN}$ was more comparable to children in the unexposed group.

Female children of women with $\mathrm{BN}$ and $\mathrm{AN}+\mathrm{BN}$ continued to have a higher BMI until 5 years (figure 4), which by 10 years was more comparable to children in the unexposed group. By comparison, female children of women with AN had a lower BMI in early childhood, which was similar to children of mothers without ED later in childhood (see figure 4). Female children of women reporting other psychiatric disorders had a similar BMI trajectory to children in the AN group, see figure 4; however, at 10 years of age, their predicted BMI was on average $0.56 \mathrm{~kg} / \mathrm{m}^{2} \quad(\mathrm{p}=0.002)$ higher than the unexposed group.

\section{DISCUSSION}

This study highlights differential patterns of growth in children of women with ED, compared to those with no ED history. Some noteworthy gender differences were apparent. 
Table 2 Mean predicted anthropometry across categories of maternal eating disorder, with adjustment for standard confounders (gestational age, maternal age, maternal education, parity)

\begin{tabular}{|c|c|c|c|c|c|c|c|c|c|c|}
\hline & \multicolumn{5}{|l|}{ Boys } & \multicolumn{5}{|l|}{ Girls } \\
\hline & \multirow[b]{2}{*}{$\begin{array}{l}\text { Mean predicted } \\
\text { anthropometry } \\
\text { (SD) of offspring } \\
\text { of unexposed } \\
\text { women }\end{array}$} & \multicolumn{4}{|c|}{$\begin{array}{l}\text { Mean difference (SD) from unexposed for offspring of } \\
\text { women with: }\end{array}$} & \multirow[b]{2}{*}{$\begin{array}{l}\text { Mean predicted } \\
\text { anthropometry } \\
\text { (SD) of offspring } \\
\text { of unexposed } \\
\text { women }\end{array}$} & \multicolumn{4}{|c|}{$\begin{array}{l}\text { Mean difference (SD) from unexposed for offspring } \\
\text { of women with: }\end{array}$} \\
\hline & & $\begin{array}{l}\text { Anorexia } \\
\text { nervosa }\end{array}$ & $\begin{array}{l}\text { Bulimia } \\
\text { nervosa }\end{array}$ & $\begin{array}{l}\text { Anorexia } \\
\text { nervosa and } \\
\text { Bulimia } \\
\text { nervosa } \\
\end{array}$ & $\begin{array}{l}\text { Other } \\
\text { psychiatric } \\
\text { disorders }\end{array}$ & & $\begin{array}{l}\text { Anorexia } \\
\text { nervosa }\end{array}$ & $\begin{array}{l}\text { Bulimia } \\
\text { nervosa }\end{array}$ & $\begin{array}{l}\text { Anorexia } \\
\text { nervosa } \\
\text { and Bulimia } \\
\text { nervosa }\end{array}$ & $\begin{array}{l}\text { Other } \\
\text { psychiatric } \\
\text { disorders }\end{array}$ \\
\hline Height (cm) & $N=4588$ & $N=74$ & $\mathrm{~N}=85$ & $\mathrm{~N}=38$ & $\mathrm{~N}=501$ & $N=4416$ & $\mathrm{~N}=65$ & $N=82$ & $\mathrm{~N}=30$ & $N=432$ \\
\hline Birth & $50.3(5.4)$ & $+0.14(2.0)$ & $+0.17(2.08)$ & $-0.10(2.0)$ & $-0.20(2.2)^{\star *}$ & $49.7(5.3)$ & $-0.47(1.9)^{*}$ & $-0.08(2.1)$ & $+0.23(2.0)$ & $-0.16(2.2)^{*}$ \\
\hline 1 year & $76.1(5.4)$ & $+0.32(2.4)$ & $+0.05(2.4)$ & $-0.09(2.4)$ & $-0.28(2.5)^{\star \star \star}$ & 74.3 (5.3) & $-0.27(2.4)$ & $+0.05(2.4)$ & $-0.73(2.4)^{\star}$ & $-0.18(2.6)^{\star}$ \\
\hline 2 years & $87.3(5.4)$ & $+0.40(3.0)$ & $+0.01(3.1)$ & $-0.10(3.0)$ & $-0.32(3.2)^{\star \star}$ & $85.6(5.3)$ & $-0.24(3.0)^{\star *}$ & +0.02 (3.0) & $-0.93(3.0)^{\star}$ & $-0.18(3.2)$ \\
\hline 5 years & $110.2(6.8)$ & $+0.39(4.5)$ & $+0.15(4.5)$ & $-0.17(4.4)$ & $-0.42(4.7)^{\star *}$ & $109.6(6.0)$ & $-0.31(4.3)$ & $-0.18(4.3)$ & $-0.94(4.2)$ & $-0.17(4.8)$ \\
\hline 10 years & 140.7 (8.8) & $-0.75(7.3)$ & $+1.88(7.5)^{\star \star \star}$ & $-0.81(7.1)$ & $-0.64(7.9)^{*}$ & $138.9(8.6)$ & $-0.57(7.0)$ & $-0.65(6.9)$ & $-0.32(6.7)$ & $-0.12(7.5)$ \\
\hline $\begin{array}{l}\text { Ponderal index } \\
\left(\mathrm{kg} / \mathrm{m}^{3}\right)\end{array}$ & $N=4537$ & $\mathrm{~N}=73$ & $N=84$ & $\mathrm{~N}=38$ & $N=496$ & $N=4363$ & $N=64$ & $\mathrm{~N}=81$ & $\mathrm{~N}=30$ & $N=424$ \\
\hline Birth & $26.1(5.4)$ & $-0.43(2.5)$ & $-0.28(2.6)$ & $+0.07(2.5)$ & $+0.13(2.7)$ & $26.2(5.3)$ & $-0.07(1.9)$ & $+0.48(2.2)^{\star *}$ & $-0.16(2.2)$ & $-0.09(2.3)$ \\
\hline 1 year & $23.3(4.7)$ & $-0.12(2.1)$ & $+0.41(2.2)^{\star}$ & $+0.27(2.1)$ & $+0.22(2.3)^{\star \star}$ & $23.2(5.3)$ & $+0.39(2.4)^{*}$ & $+0.06(2.5)$ & $+0.39(2.7)$ & $-0.22(2.7)^{\star}$ \\
\hline BMI $\left(\mathrm{kg} / \mathrm{m}^{2}\right)$ & $\mathrm{N}=4271$ & $\mathrm{~N}=68$ & $\mathrm{~N}=788.31$ & $\mathrm{~N}=35$ & $\mathrm{~N}=452$ & $\mathrm{~N}=4117$ & $\mathrm{~N}=61$ & $\mathrm{~N}=78$ & $\mathrm{~N}=29$ & $\mathrm{~N}=398$ \\
\hline 2 years & $16.8(3.9)$ & $+0.10(2.0)$ & $+0.26(1.9)$ & $+0.32(1.7)$ & $+0.15(2.0)^{\star}$ & 16.6 (3.9) & $-0.35(1.9)^{*}$ & $+0.3(1.9)$ & $+0.25(1.8)$ & $-0.07(2.1)$ \\
\hline 5 years & 15.9 (3.9) & $+0.34(1.4)^{\star \star}$ & $+0.12(1.3)$ & $+0.49(1.4)^{\star *}$ & $-0.02(1.5)$ & $16.0(3.9)$ & $-0.01(1.5)$ & $+0.26(1.5)^{\star}$ & $+0.32(1.5)$ & $+0.16(2.1)^{\star \star}$ \\
\hline 10 years & $17.7(4.6)$ & +0.09 (3.3) & $+0.12(3.2)$ & +0.08 (3.2) & +0.09 (3.6) & $18.1(5.1)$ & $+0.03(3.5)$ & $-0.29(3.4)$ & -0.52 (3.3) & $+0.56(3.7)^{\star \star \star}$ \\
\hline \multicolumn{11}{|c|}{$\begin{array}{l}\text { Values are predicted from the multilevel models, and represent the predicted anthropometry for offspring of mean gestational age ( } 39.4 \text { weeks) and with a mother with the following } \\
\text { characteristics: mean age ( } 28.2 \text { years), less than O-level education, parity of zero. P values are from Z-tests comparing each group to the offspring of women with no eating or other psychiatric }\end{array}$} \\
\hline
\end{tabular}


Table 3 Predicted anthropometry across categories of maternal eating disorder, with adjustment for standard confounders (gestational age, maternal age, maternal education, parity) and potential mediators (maternal pre-pregnancy BMI and smoking during pregnancy)

Boys

Girls

women with:

\section{Mean predicted} anthropometry

(SD) of

offspring of unexposed

women

Height (cm)

Birth

1 year

2 years

5 years

$50.3(5.4)$

$76.2(5.4)$

$87.4(5.4)$

$\left(\mathrm{kg} / \mathrm{m}^{3}\right)$

Birth $\quad 26.2(5.4)$

1 year

2 years $\quad 16.8(3.92)$

5 years $\quad 15.9(3.92)$

10 years $\quad 17.7(4.57)$

+0.21 (2.0)

$+0.47(3.0)^{*}$

$+0.47(4.5)$

-0.64 (7.3)

$\mathrm{N}=73$
Ponderal index $\mathrm{N}=4537$

BMI $\left(\mathrm{kg} / \mathrm{m}^{2}\right) \quad \mathrm{N}=4271$

\section{Mean difference (SD) from}

Mean predicted unexposed for offspring of women with:

anthropometry

(SD) of

nervosa and Other offspring of

Bulimia psychiatric unexposed

women

nervosa nervosa

nervosa

disorders

$+0.04(2.0) \quad-0.13(2.2)^{*}$

$49.8(5.3)$

+0.05 (2.4)

+0.05 (2.4)

$74.3(5.3)$

$+0.01(3.1)$

$+0.04(3.0)$

$-0.25(3.2)^{\star}$

$85.7(5.3)$

$+1.89$

$-0.04(4.4)$

$-0.34(4.7)^{\star} \quad 109.7(6.0)$

$\mathrm{N}=84$

$\mathrm{N}=38$

$\mathrm{N}=496$

$138.9(8.6)$

$-0.37(2.49) \quad-0.29(2.6)$

+0.08 (2.5)

$-0.07(2.14)+0.39(2.2)^{*}$

$\mathrm{N}=68 \quad \mathrm{~N}=78$

$+0.28(2.1)$

$+0.11(2.7)$

$\mathrm{N}=4363$

$+0.43(1.4)^{\star \star \star}+0.11(1.4)$

$\mathrm{N}=35$

$26.3(5.3)$

$23.3(5.3)$

$+0.33(1.8) \quad+0.13(2.0)^{\star} \quad 16.6(3.9)$

$+0.17(3.2) \quad+0.11(3.2)$

$-0.05(1.5)$

+0.08 (3.2)

Anorexia

nervosa

and

nervosa nervosa nervosa
$-0.219(2.6)^{*}$

$+0.19(2.0) \quad+0.27(2.0)$

Anorexia Bulimia Bulimia psychiatric

disorders

$-0.41(1.9)^{*}-0.04(2.1) \quad+0.30(2.0)-0.09(2.2)$

$-0.2(2.4)+0.09(2.4) \quad-0.68(2.4)^{*}-0.11(2.6)$

$-0.18(3.0)+0.06(3.0)-0.88(3.0)^{*}-0.11(3.2)$

$-0.25(4.3) \quad-0.14(4.3) \quad-0.88(4.2)-0.10(4.6)$

$-0.52(6.2) \quad-0.61(6.9) \quad-0.26(6.7) \quad-0.05(7.5)$

$\mathrm{N}=64 \quad \mathrm{~N}=81 \quad \mathrm{~N}=30 \quad \mathrm{~N}=424$

$-0.12(2.2)+0.47(2.2)^{\star *}-0.22(2.2)-0.07(2.3)$

$+0.34(2.4)+0.05(2.5) \quad+0.35(2.7) \quad-0.20(2.7)^{*}$

$\mathrm{N}=61 \quad \mathrm{~N}=78 \quad \mathrm{~N}=29 \quad \mathrm{~N}=398$

$-0.26(1.9)+0.32(1.9) \quad+0.37(1.8)-0.08(2.1)$

$+0.08(1.5)+0.29(1.5)^{\star}+0.45(1.5)^{*}+0.15(1.6)^{\star *}$

$-0.09(3.5)-0.26(3.4)-0.39(3.2)+0.56(3.7)^{\star \star *}$

Values are predicted from the multilevel models, and represent the predicted anthropometry for offspring of mean gestational age (39.4 weeks) and with a mother with the following

characteristics: mean age (28.2 years), less than O-level education, parity of zero, mean prepregnancy BMI (22.94 kg/ $\left.\mathrm{m}^{2}\right)$, non-smoker during pregnancy. P values are from Z-tests comparing

each group to the offspring of women with no eating or other psychiatric disorder.

${ }_{* \star *}^{*} \leq 0.1$.

${ }_{* \star *}^{*}<0.05$.

${ }^{* * *} p<0.01$

BMI, body mass index. 


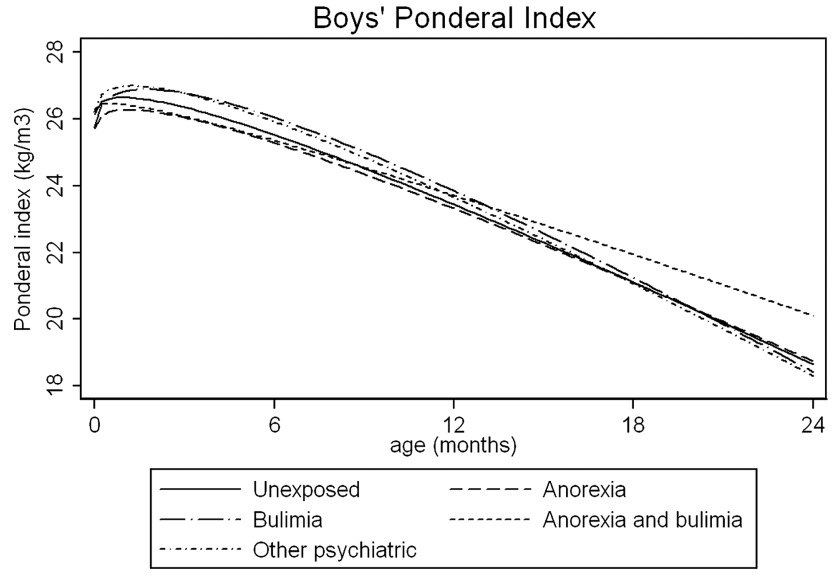

Figure 1 Average fractional polynomial curve of ponderal index trajectories for boys by maternal eating disorder, birth to 2 years, adjusted for confounders. Values are predicted from the multilevel models, and represent the predicted anthropometry for offspring of mean gestational age (39.4 weeks) and with a mother with the following characteristics: mean age (28.2 years), less than O-level education, parity of zero

\section{Adipose}

Previous research has suggested that children of women with $\mathrm{BN}$ may be particularly vulnerable to being overweight or obese ${ }^{7}{ }^{18}$; in the present investigation, higher adiposity was not specific to maternal $\mathrm{BN}$ but was present in male children in all maternal ED groups, and most pronounced at the age of 5. These growth differentials are possibly specific to maternal eating pathology, rather than more general psychopathology, since male children of women with other psychiatric disorders had comparable BMI trajectories to children of mothers

Boys' BMI

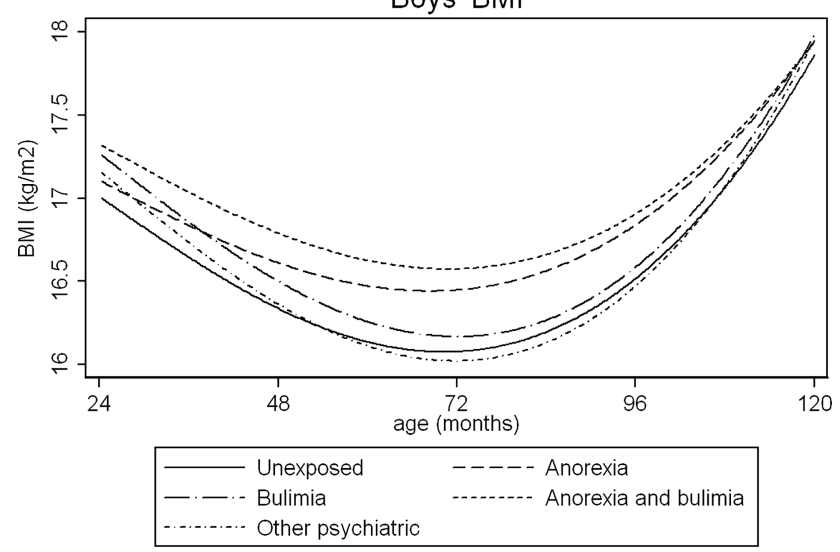

Figure 2 Average fractional polynomial curve of BMI trajectories for boys by maternal eating disorder, 2-10 years, adjusted for confounders. Values are predicted from the multilevel models, and represent the predicted anthropometry for offspring of mean gestational age (39.4 weeks) and with a mother with the following characteristics: mean age (28.2 years), less than O-level education, parity of zero. BMI, body mass index.

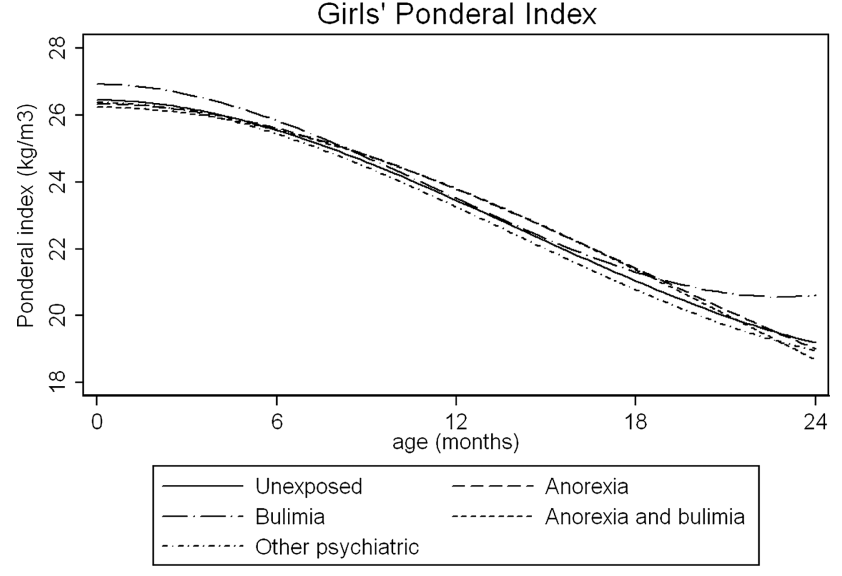

Figure 3 Average fractional polynomial curve of ponderal index trajectories for girls by maternal eating disorder, birth to 2 years, adjusted for confounders. Values are predicted from the multilevel models, and represent the predicted anthropometry for offspring of mean gestational age (39.4 weeks) and with a mother with the following characteristics: mean age (28.2 years), less than O-level education, parity of zero.

without ED. Rapid growth in childhood may increase the risk of obesity and health problems later in life; it will therefore be important to follow-up the health and development of these children during adolescence.

The BMI trajectories of female children of women with ED fluctuated throughout childhood, and female children of women with $\mathrm{BN}$ and $\mathrm{AN}+\mathrm{BN}$ tended to have a higher BMI in early childhood but lower at 10 years, whereas the opposite pattern was found in female children of women with AN, who had higher BMI in early childhood but more comparable BMI by the age of

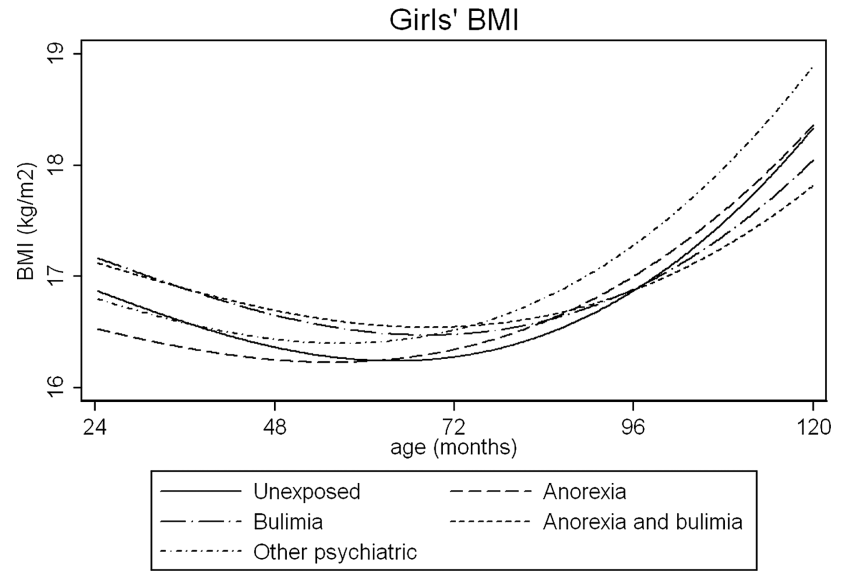

Figure 4 Average fractional polynomial curve of BMI trajectories for girls by maternal eating disorder, 2-10 years, adjusted for confounders. Values are predicted from the multilevel models, and represent the predicted anthropometry for offspring of mean gestational age (39.4 weeks) and with a mother with the following characteristics: mean age (28.2 years), less than O-level education, parity of zero. BMI, body mass index. 
10 years. It was not an aim of this study to investigate the relationship between children's growth and food intake; however, it is possible that the observed differences in growth among children of mothers with AN may be related to changes in dietary patterns across childhood. We have previously reported that female children of women with AN show greater adherence to a 'health conscious/vegetarian' dietary pattern, which diminished across childhood. ${ }^{13}$ Further research is necessary to investigate this hypothesised association between childhood growth and dietary patterns in this particular group of children.

\section{Height}

In this study, male children of women with BN were found to be taller with a higher BMI from 2 years onwards, compared with children of women without ED. In contrast, male children of women with AN were taller in early childhood but shorter by the age of 10 years. Furthermore, male children of women with a history of $\mathrm{AN}$ and $\mathrm{BN}$ were shorter throughout childhood. Similarly, female children of women with ED, particularly lifetime AN, tended to be shorter than children of mothers without ED. Taken together, these findings suggest that children of mothers with AN may be at particular risk for stunted growth during childhood. These findings are in line with previous case studies and studies of growth among younger children of women with ED, which have indicated reduced growth among children of women with AN. ${ }^{17} 1820$

In the ED groups, height differentials were found to widen over childhood while remaining stable in children of mothers with other psychiatric disorders. This study raises interesting questions regarding the underlying mechanisms for differential patterns of growth in children of mothers with ED, which warrant further investigation. The findings may suggest that height differences in children of women with other psychiatric disorders are possibly driven by intrauterine processes, whereas for the ED group differences in growth are more likely to be due to postnatal factors, such as feeding and diet. ${ }^{30}$ However, the factors contributing to the differential patterns of growth observed in this study are likely to be multifactorial and include biological, psychological and social pathways, which were beyond the scope of the present investigation. Further studies are required to determine the underlying mechanisms for the associations found in this study.

\section{Gender differences}

Previous investigations suggest that mothers with ED show greater concern for their daughter's weight and shape than sons, ${ }^{9}$ who may have a higher risk of being underweight. ${ }^{18}$ Our findings support the idea of genderspecific growth trajectories of children of women with ED; however, since our growth models were constructed separately for males and females, it was not possible to formally test gender interactions. Differences should therefore be treated with caution and require replication in other studies.

\section{Strengths and limitations}

The main strengths of this study are its uniqueness in examining growth trajectories longitudinally, in a large sample with a large number of repeated measurements and information on potential confounding factors. Our modelling approach allowed us to examine growth trajectories across childhood, taking into account the different timings and numbers of measurements between children, and enabled us to explore the associations of maternal ED with child growth at a range of ages within the same children.

However, maternal ED classification was made on the basis of maternal self-report and according to lifetime history, which may be subject to bias and may represent a wide range of ED severities and ages/duration of illness. This measure also does not allow for an investigation of the associations of current ED symptoms and childhood growth. Furthermore, the number of women within each of the ED groups was relatively small, and it is therefore possible that negative findings are a result of small sample size.

PI and BMI are the most commonly used methods of evaluating adiposity in children, particularly in large prospective cohort studies. Nevertheless, BMI remains associated with height in children, with taller children on average having a higher BMI. We think this is unlikely to have biased our results, which generally show shorter height and greater BMI in the children of women with ED. However, it will be interesting if future studies investigate direct measures of fat mass in this sample using dual emission X-ray absorptiometry.

\section{CONCLUSION}

The present investigation highlights several new findings regarding the growth of children of mothers with ED. Specifically, these findings indicate that female children of women with AN have an increased risk for reduced growth in early childhood, while the risk of more rapid growth may be apparent in male children of mothers with ED. This is the first longitudinal study of growth trajectories in this group, and our findings require replication and further examination of the pathways underlying differences in childhood growth trajectories. Nevertheless, health professionals should be aware of the potential associations between maternal ED and growth in their children, in order to monitor their health and development. At a public health level, given the rise in obesity, it will be important to explore the underlying mechanisms of growth differences in children of women with ED.

Acknowledgements The authors are extremely grateful to all the families who took part in this study, the midwives for their help in recruiting them and the whole ALSPAC team, which includes interviewers, computer and laboratory technicians, clerical workers, research scientists, volunteers, managers, receptionists and nurses. 
Contibutors AE contributed to the conceptualisation and design of the study and the interpretation of the data. She drafted the initial article and approved the final manuscript as submitted. LDH conducted the statistical analysis and contributed to the interpretation of the data and drafting of the initial article. She reviewed and revised the article and approved the final manuscript as submitted. KT contributed to the statistical analysis strategy and the interpretation of the data and approved the final manuscript as submitted. JT and US contributed to the interpretation of the data, critically reviewed and revised the manuscript and approved the final manuscript as submitted. NM contributed to the conceptualisation and design of the study and the interpretation of the data. She also reviewed and revised the manuscript.

Funding This article presents independent research commissioned by the National Institute for Health Research (NIHR) under its Programme Grants for Applied Research scheme (RP-PG-0606-1043). This research was funded by a National Institute of Health Research (NIHR) clinician scientist award (DHCS/08/08/012) to Dr N Micali. The views and opinions expressed in this publication are those of the authors and do not necessarily reflect those of the National Health Service (NHS), NIHR or the DH. Laura D Howe was funded by a grant from the UK Economic and Social Research Council grant that provided her salary at the start of this work (RES-060-23-0011) and by a UK Medical Research Council Population Health Scientist Fellowship (G1002375) at the end of this work.

\section{Competing interests None.}

Ethics approval The study was approved by the Institute of Psychiatry Ethics Committee (Ref 110/02) and the Avon Longitudinal Study of Parents and Children (ALSPAC) Law and Ethics Committee and the Local Research Ethics Committees.

Provenance and peer review Not commissioned; externally peer reviewed.

Data sharing statement ALSPAC encourage data sharing to maximise use of the resource, so the executive may put researchers in touch with other groups working in the same area. The vast majority of the data are available for use on request and for these data that are not considered of overlap. ALSPAC data access and sharing policy can be found here http://www.bristol.ac.uk/alspac/ researchers/data-access/policy/

Open Access This is an Open Access article distributed in accordance with the Creative Commons Attribution Non Commercial (CC BY-NC 3.0) license, which permits others to distribute, remix, adapt, build upon this work noncommercially, and license their derivative works on different terms, provided the original work is properly cited and the use is non-commercial. See: http:// creativecommons.org/licenses/by-nc/3.0/

\section{REFERENCES}

1. Van Hoeken D, Seidell J, Hoek HW, Epidemiology. In: Treasure J, Schmidt UVan Furth EF, eds. Handbook of eating disorders. Wiley Online Library, 2003:11-34.

2. American Psychiatric Association, Diagnostic and statistical manual of mental disorders: DSM-IV-TR.4th edn. Washington: American Psychiatric Publishing, Inc, 2000.

3. Ramchandani $P$, Stein A. The impact of parental psychiatric disorder on children: avoiding stigma, improving care. BMJ 2003;327:242-3.

4. Park RJ, Senior R, Stein A. The offspring of mothers with eating disorders. Eur Child Adolesc Psychiatry 2003;12:1110-19.

5. Kothari R, Solmi F, Treasure J, et al. The neuropsychological profile of children at high risk of developing an eating disorder. Psychol Med 43:1543-54.
6. Patel P, Wheatcroft R, Park RJ, et al. The children of mothers with eating disorders. Clin Child Fam Psychol Rev 2002;5:1-19.

7. Micali N, Simonoff E, Treasure J. Infant feeding and weight in the first year of life in babies of women with eating disorders. $J$ Pediatr 2009;154:55-60.

8. Reba-Harrelson L, Von Holle A, Hamer RM, et al. Patterns of maternal feeding and child eating associated with eating disorders in the Norwegian Mother and Child Cohort Study (MoBa). Eat Behav 2010;11:54-61.

9. Agras S, Hammer L, McNicholas F. A prospective study of the influence of eating-disordered mothers on their children. Int $J$ Eat Disord 1999;25:253-62.

10. Stein A, Woolley H, McPherson K. Conflict between mothers with eating disorders and their infants during mealtimes. $\mathrm{Br} J$ Psychiatry 1999;175:455-61.

11. Stein A, Woolley H, Cooper SD, et al. An observational study of mothers with eating disorders and their infants. J Child Psycho Psychiatry 1994;35:733-48.

12. Waugh E, Bulik CM. Offspring of women with eating disorders. Int $J$ Eat Disord 1999;25:123-33.

13. Easter A, Naumann U, Northstone K, et al. A longitudinal investigation of nutrition and dietary patterns in children of mothers with eating disorders. J Pediatr 2013;163:173-8.

14. Treasure JL, Russell GF. Intrauterine growth and neonatal weight gain in babies of women with anorexia nervosa. BMJ (Clin Res Ed) 1988;296:1038

15. Micali N, Simonoff E, Treasure J. Risk of major adverse perinata outcomes in women with eating disorders. Br J Psychiatry 2007;190:255-9.

16. Stein $\mathrm{A}$, Woolley $\mathrm{H}$. The influence of parental eating disorders on young children: implications of recent research for some clinical interventions. Eat Disord 1996;4:139-46.

17. van Wezel-Meijler G, Wit JM. The offspring of mothers with anorexia nervosa: a high-risk group for undernutrition and stunting? Eur $J$ Pediatr 1989;149:130-5.

18. Hodes M, Timimi S, Robinson P. Children of mothers with eating disorders: a preliminary study. Eur Eat Disord Rev 1997;5:11-24

19. Stein A, Fairburn CG. Children of mothers with bulimia nervosa. BMJ 1989;299:777-8.

20. Timimi S, Robinson P. Disturbances in children of patients with eating disorders. Eur Eat Disord Rev 1996;4:183-8.

21. Stein A, Murray L, Cooper P, et al. Infant growth in the context of maternal eating disorders and maternal depression: a comparative study. Psychol Med 1996;26:569-74.

22. Stein A, Woolley $\mathrm{H}$, Cooper $\mathrm{S}$, et al. Eating habits and attitudes among 10-year-old children of mothers with eating disorders: longitudinal study. Br J Psychiatry 2006;189:324-9.

23. Golding J, Pembrey M, Jones R. ALSPAC—-the Avon Longitudinal Study of Parents and Children. I. Study methodology. Paediatr Perinat Epidemiol 2001;15:74-87.

24. Boyd A, Golding J, Macleod J, et al. Cohort profile: the 'children of the 90s'-the index offspring of the Avon Longitudinal Study of Parents and Children. Int J Epidemiol 2012;42:111-27.

25. Fraser $\mathrm{A}$, Macdonald-Wallis $\mathrm{C}$, Tilling $\mathrm{K}$, et al. Cohort profile: the Avon Longitudinal Study of Parents and Children: ALSPAC mothers cohort. Int J Epidemiol 2012;42:97-110.

26. Micali N, Treasure J, Simonoff E. Eating disorders symptoms in pregnancy: a longitudinal study of women with recent and past eating disorders and obesity. J Psychosom Res 2007;63:297-303.

27. Rasbash J, Charlton C, Browne WJ, et al. MLwiN version 2.02. Centre for Multilevel Modelling, University of Bristol, 2005.

28. Howe LD, Tilling K, Lawlor DA. Accuracy of height and weight data from child health records. Arch Dis Child 2009;94:950-4.

29. Dubois L, Girad M. Accuracy of maternal reports of pre-schoolers' weights and heights as estimates of BMI values. Int $\mathrm{J}$ Epidemiol 2007:36:132-8.

30. Howe LD, Tilling K, Galobardes B, et al. Socioeconomic differences in childhood growth trajectories: at what age do height inequalities emerge? J Epidemiol Community Health 2010;66:143-8. 